
\title{
28 Research Suare \\ First report of Blastocystis infection in pigs from large-scale farms in Xinjiang, China
}

\author{
Rongjun Wang \\ Henan Agricultural University \\ Ying Zhang \\ Tarim University \\ Yuxi Jiang \\ Henan Agricultural University \\ Jinming Xing \\ Tarim University \\ Dayong Tao \\ Tarim University \\ Longxian Zhang \\ Henan Normal University \\ Meng Qi ( $\sim$ qimengdz@163.com )
}

\section{Research}

Keywords: Blastocystis, SSU rRNA, genetic polymorphism, pig, Xinjiang

Posted Date: January 7th, 2020

DOl: https://doi.org/10.21203/rs.2.20161/v1

License: (c) (1) This work is licensed under a Creative Commons Attribution 4.0 International License.

Read Full License 


\section{Abstract}

Background:

Blastocystis is a commonly identified intestinal protozoan in humans and various animals. Few studies are available regarding the genetic characterization of Blastocystis infections in pigs in China.

Methods:

In this study, 801 fecal samples were collected from seven large-scale pig farms in Xinjiang and tested by polymerase chain reaction.

Results:

The average infection rate of Blastocystis was 21.7\% (174/801); the infection rates for pre-weaning piglets, post-weaning piglets, fattening pigs, and sows were $7.1 \%, 10.0 \%, 31.8 \%$, and $41.9 \%$, respectively $(\chi 2=104.89 ; P<0.01)$. Blastocystis subtypes ST1 $(n=7)$, ST3 $(n=2)$, and ST5 $(n=165)$ were identified using sequence analysis of the small-subunit ribosomal RNA gene, with subtype ST 5 being predominant in each of the pig farms. All the age groups were positive for Blastocystis. ST3 and ST5 were identified in pre-weaning piglets, and ST1, ST3, and ST5 in post-weaning piglets. In contrast, only the ST5 subtype was observed in fattening pigs and sows. Genetic polymorphisms were observed at the intra-subtype level, including two variations for ST1 (ST1A, ST1B), and seven for ST5 (ST5A to ST5G), by sequence alignment analysis and phylogenetic analysis.

Conclusions:

A high prevalence of Blastocystis was detected in pigs in Xinjiang, China. The infection rate increased significantly with increasing age of the pigs. ST5 was the predominant Blastocystis subtype in all age groups. Subtypes ST1, ST3, and ST5 may emerge as zoonotic pathogens in some areas of China because of the large scale of the pork industry and close contact between pigs and humans. More studies are needed to elucidate the transmission and public health significance of Blastocystis in pigs in various areas. Key words: Blastocystis, SSU rRNA, genetic polymorphism, pig, Xinjiang

\section{Background}

Blastocystis, a common intestinal parasite, can infect a wide spectrum of hosts, including humans, other mammals, birds, amphibians, reptiles, fish, arthropods, and annelids [1]. Although the controversy regarding the pathogenicity of this pathogen continues, some studies have suggested that Blastocystis infection is associated with various gastrointestinal disorders, irritable bowel syndrome, and cutaneous lesions [2,3]. Molecular studies in recent decades have indicated that there is extensive genetic variation within the genus Blastocystis. To date, at least 17 subtypes have been described (ST1 to ST17), based on molecular analyses of the small-subunit ribosomal RNA (SSU rRNA). Among them, ST1 to ST9, and ST12 are detected in both domestic animals and humans, while ST10, ST11, ST13 to ST17 are exclusively 
identified in nonhuman animals [4-7]. ST3 is the most commonly detected subtype in humans, followed by ST1, ST2, and ST4, whereas ST 5 to ST9 are seldom observed $[8,9]$. In general, the distribution of Blastocystis subtypes varies in different animal species and geographical areas [10].

Blastocystis infection in pigs has been reported in Spain, Japan, Thailand, the Philippines, China, the United States, the United Kingdom, Vietnam, Australia, Cambodia, Indonesia, Brazil, and India, with the infection rate ranging from $7.5-100 \%[1,4,5,9,11-21]$. Seven subtypes, ST1, ST2, ST3, ST5, ST6, ST7, and ST10, have been identified in pigs in various parts of the world [22]. The zoonotic risk of transmission of Blastocystis by pigs has been predicted by a study in Australia where the zoonotic subtype ST5 was detected in both pigs and piggery workers [20,23]. Likewise, the zoonotic subtypes ST1, ST3, and ST5 were also identified in pigs and pig handlers in Thailand [24].

In China, humans and domestic and wild animals have shown a high prevalence of Blastocystis infection in a number of provinces, ten known (ST1 to ST7, ST10, ST13, ST14), and four novel (Novel 1 to Novel 4) subtypes have been reported [10]. However, only three studies have been published on Blastocystis infection in pigs in Jiangxi, Shaanxi, and Heilongjiang provinces, with the overall prevalence being $66.4 \%$ $(441 / 664)$ and with ST1, ST3, ST5, and ST10 having been identified [11, 22, 25]. Thus far, no report is available regarding Blastocystis in domestic animals in Xinjiang Uygur Autonomous Region (hereafter referred to as Xinjiang), China. The aim of this study was to estimate the prevalence and genetic polymorphism of Blastocystis infection in pigs in Xinjiang, China.

\section{Methods}

Specimen collection

A total of 801 fresh stool samples were collected from 169 pre-weaning piglets ( $<20$ days old), 281 postweaning piglets ( $21-70$ days old), 129 fattening pigs (71-180 days old), and 222 sows ( $>181$ days old) from seven large-scale pig farms in Xinjiang between September 2017 and June 2018. Each of the sampled farms had from 10,000 to 80,000 pigs. These farms were visited on a single occasion and stool samples were randomly collected from the animals by a veterinarian. At the time of collection, no diarrhea was apparent in the herds. Using sterile gloves, stool samples were collected directly from the rectum or immediately from fresh feces deposited on the ground after defecation. The fresh feces were placed in clean plastic bags marked with the date, age, and farm, and immediately placed onto ice packs in an insulated container. Specimens were transported to the laboratory, stored at $4{ }^{\circ} \mathrm{C}$ and processed no later than a week after collection.

DNA extraction and PCR amplification

Genomic DNA of Blastocystis was extracted from approximately $200 \mathrm{mg}$ of each fecal sample using the E.Z.N.A.R® Stool DNA Kit (D4015-02, Omega Bio-Tek Inc., Norcross, GA, USA). Extracted DNA specimens were used as a template for polymerase chain reaction (PCR)-based analyses. Positive (human-derived Blastocystis subtype ST1 DNA) and negative controls (distilled water) were included in each PCR assay. 
The identity of Blastocystis subtypes was confirmed on the basis of the SSU rRNA gene, with the primers (forward: 5' GGA GGT AGT GAC AAT AAA TC 3'; reverse: 5' TGC TTT CGC ACT TGT TCA TC 3') being adopted from a previous study [5]. Each 50- $\mu \mathrm{L}$ PCR mixture contained $1 \times$ PCR buffer, $1.5 \mathrm{mM} \mathrm{MgSO}_{4}$, 0.2 mM dNTPs, 1 U KOD-Plus- (Toyobo Co. Ltd, Osaka, Japan), $1 \mu \mathrm{M}$ of each primer. A total of 35 cycles, each consisting of $95{ }^{\circ} \mathrm{C}$ for $35 \mathrm{~s}, 55^{\circ} \mathrm{C}$ for $35 \mathrm{~s}$, and $72{ }^{\circ} \mathrm{C}$ for $45 \mathrm{~s}$, was performed; an initial preheat step at $95^{\circ} \mathrm{C}$ for $5 \mathrm{~min}$ and a final extension step at $72{ }^{\circ} \mathrm{C}$ for $10 \mathrm{~min}$ were also included.

Sequencing and phylogenetic analyses

Positive PCR products were sequenced by Genewiz (Suzhou, China); the accuracy of each nucleotide sequence was confirmed by two-directional sequencing. The subtypes of Blastocystis were determined by alignment analyses of the nucleotide sequences using the program ClustalX 2.01

(http://www.clustal.org/). Phylogenetic analysis adopted a neighbor-joining model of the aligned sequences implemented in MEGA7 (http://www.megasoftware.net/), with 1,000 replicates to assess the robustness of clusters. The nucleotide sequences in this paper were deposited in the GenBank database under accession numbers MN326610-MN326619.

Statistical analysis

Differences in prevalence between ages and farms were compared with the $\chi^{2}$ test in SPSS for Windows (Release 13.0 standard version; SPSS Inc., Chicago, IL, USA). Differences of $P<0.05$ were considered significant.

\section{Results}

Prevalence of Blastocystis

Blastocystis was identified in 174 (21.7\%) out of 801 fecal samples by PCR analysis of samples from the seven pig farms investigated (Table 1). The infection rate varied among different pig farms, with the highest $(46 / 99 ; 46.5 \%)$ and lowest $(6 / 98 ; 6.1 \%)$ prevalence being observed in Baicheng and Marabishi, respectively $\left(\chi^{2}=82.74 ; P<0.005\right)$ (Table 1$)$. The infection rates for pre-weaning piglets, post-weaning piglets, fattening pigs, and sows were $7.1 \%, 10.0 \%, 31.8 \%$, and $41.9 \%$, respectively $\left(X^{2}=104.89 ; P<0.01\right)$ (Table 2). 
Table 1

The prevalence and subtype distribution of Blastocystis on each pig farm in Xinjiang.

\begin{tabular}{|lll|}
\hline $\begin{array}{l}\text { Collection } \\
\text { site }\end{array}$ & $\begin{array}{l}\text { No. positive/No. } \\
\text { sample (\%) }\end{array}$ & Subtype (No.) \\
\hline Marabishi & $6 / 98(6.1 \%)$ & ST5A (1), ST5B (1), ST5C (3), ST5D (1) \\
\hline Alaer & $20 / 95(21.1 \%)$ & ST5A (2), ST5B (6), ST5C (12) \\
\hline Yarkant & $13 / 130(10.0 \%)$ & ST5A (4), ST5B (8), ST5C (1) \\
\hline Baicheng & $46 / 99(46.5 \%)$ & $\begin{array}{l}\text { ST1A (1), ST3A (1), ST5A (2), ST5B (9), ST5C (12), ST5E (18), ST5F } \\
(3)\end{array}$ \\
\hline Shaya & $40 / 100(40.0 \%)$ & $\begin{array}{l}\text { ST1A (4), ST1B (2), ST5A (3), ST5B (8), ST5C (7), ST5E (4), ST5F } \\
(10), \text { ST5G (2) }\end{array}$ \\
\hline Changji & $22 / 130(16.9 \%)$ & ST5A (1), ST5B (8), ST5C (3), ST5F (2), ST5G (8) \\
Ruoqiang & $27 / 149(18.1 \%)$ & ST3A (1), ST5A (1), ST5B (8), ST5C (10), ST5E (1), ST5F (6) \\
\hline Total & $174 / 801(21.7 \%)$ & $\begin{array}{l}\text { ST1A (5), ST1B (2), ST3A (2), ST5A (14), ST5B (48), ST5C (48), } \\
\text { ST5D (1), ST5E (23), ST5F (21), ST5G (10) }\end{array}$ \\
\hline
\end{tabular}

Table 2

Blastocystis subtypes identified among different age groups of pigs in Xinjiang.

\begin{tabular}{|lll|}
\hline Age group & $\begin{array}{l}\text { No. positive/No. } \\
\text { sample (\%) }\end{array}$ & Subtype (No.) \\
\hline $\begin{array}{l}\text { Pre-weaning } \\
\text { piglets }\end{array}$ & $12 / 169(7.1 \%)$ & ST3A (1), ST5A (1), ST5B (10) \\
$\begin{array}{l}\text { Post-weaning } \\
\text { piglets }\end{array}$ & $28 / 281(10.0 \%)$ & $\begin{array}{l}\text { ST1A (5), ST1B (2), ST3A (1), ST5A (4), ST5B (3), ST5C (7), } \\
\text { ST5E (3), ST5F (3) }\end{array}$ \\
\hline Fattening pigs & $41 / 129(31.8 \%)$ & ST5B (5), ST5C (14), ST5E (16), ST5F (4), ST5G (2) \\
\hline Sows & $93 / 222(41.9 \%)$ & $\begin{array}{l}\text { ST5A (9), ST5B (30), ST5C (27), ST5D (1), ST5E (4), ST5F } \\
(14), \text { ST5G (8) }\end{array}$ \\
\hline
\end{tabular}

Distribution of Blastocystis subtypes

Sequencing analysis of the SSU rRNA gene revealed the presence of three Blastocystis subtypes, ST1 (7/174), ST3 (2/174), and ST5 (165/174) (Table 1). One to three subtypes were detected on each pig farm. Subtype ST 5 was dominant in each of the pig farms surveyed, with more ST5B isolates being found in Alaer and Yarkant, ST5C in Ruoqiang, ST5E in Baicheng, and ST5F in Shaya (Table 1).

Age patterns of Blastocystis subtypes 
All the age groups were positive for Blastocystis. ST3 and ST5 were identified in pre-weaning piglets, and ST1, ST3, and ST5 in post-weaning piglets. In contrast, only the ST5 subtype was observed in fattening pigs and sows (Table 2).

The polymorphic nature of the SSU rRNA gene of Blastocystis

Seven variations of the ST 5 subtype were identified by sequence alignment analysis, with the similarity ranging from 95.4-99.8\%. ST5B and ST5C, each comprising 48 isolates, were the two dominant subtypes, followed by ST5E $(n=23)$ and ST5F $(n=21)$. Subtypes ST5A, ST5G, and ST5D were detected in 14,10 , and one sample, respectively (Table 1). In contrast, only one and two variations were identified in ST3 and ST1, respectively (Table 1). Among these subtypes, ST5G represented a new variation. Phylogenetic analysis also confirmed the polymorphic nature of the SSU rRNA gene of Blastocystis isolates in this study (Fig. 1).

\section{Discussion}

An overall infection rate of $21.7 \%$ was seen in pigs in Xinjiang, which was higher than that in Aragon, Spain (7.5\%), and Heilongjiang, China (8.8\%), but lower than the $55.3 \%$ average prevalence in pigs worldwide (Table 3). Blastocystis infection was associated with the age of the pigs in this study: the infection rate increased with increasing age (Table 2). Thus, the present findings were similar to previous investigations in which a high prevalence of Blastocystis infection was found in older pigs [22, 26]. Nevertheless, different prevalence of parasites in various studies may be caused by many factors, such as the testing method, age of the animals, sample size, host health status, timing of sample collection, and geo-ecological conditions [27]. 
Table 3

The infection rate and subtypes of Blastocystis in pigs in different countries.

\begin{tabular}{|c|c|c|c|c|c|}
\hline Countries/regions & $\begin{array}{l}\text { Sample } \\
\text { size }\end{array}$ & $\begin{array}{l}\text { Prevalence } \\
\text { (\%) }\end{array}$ & Subtypes (No.) & $\begin{array}{l}\text { Examination } \\
\text { methods }\end{array}$ & References \\
\hline $\begin{array}{l}\text { United Kingdom } \\
\text { (England) }\end{array}$ & 60 & $60 \%$ & Unidentified & Microscopy & [28] \\
\hline Zimbabwe & 412 & $82.8 \%$ & Unidentified & Microscopy & [26] \\
\hline Spain (Aragon) & 360 & $7.5 \%$ & Unidentified & PCR & [12] \\
\hline Japan (Osaka) & 61 & $95.0 \%$ & Unidentified & Microscopy & [13] \\
\hline $\begin{array}{l}\text { Thailand } \\
\text { (Chonburi) }\end{array}$ & 26 & $76.9 \%$ & ST3 (1) & PCR & [14] \\
\hline Japan (Osaka) & 34 & $44.1 \%$ & $\begin{array}{l}\text { ST1 (3), ST3 (2), ST6 } \\
(13), \text { ST1 + ST6 (1) }\end{array}$ & PCR & [15] \\
\hline Philippines (Lipa) & 12 & $100.0 \%$ & Unidentified & PCR & [16] \\
\hline China (Jiangxi) & 16 & $100.0 \%$ & ST5 (16) & PCR & [11] \\
\hline Spain (Unknown) & 395 & $46.8 \%$ & ST1 (5), ST5 (3) & $\begin{array}{l}\text { Microscopy } \\
\text { and PCR }\end{array}$ & [17] \\
\hline $\begin{array}{l}\text { United States } \\
\text { (Unknown) }\end{array}$ & 7 & $100.0 \%$ & ST5 (7) & PCR & [5] \\
\hline $\begin{array}{l}\text { United Kingdom } \\
\text { (Unknown) }\end{array}$ & 7 & $58.6 \%$ & ST5 (1) & PCR & [9] \\
\hline $\begin{array}{l}\text { Vietnam } \\
\text { (Unknown) }\end{array}$ & 12 & $100.0 \%$ & ST5 (12) & PCR & [9] \\
\hline $\begin{array}{l}\text { Australia } \\
\text { (Queensland) }\end{array}$ & 240 & $76.7 \%$ & $\begin{array}{l}\text { ST1 (4), ST3 (4), ST5 } \\
(167)\end{array}$ & PCR & [20] \\
\hline $\begin{array}{l}\text { Cambodian } \\
\text { (Dong village) }\end{array}$ & 73 & $45.2 \%$ & ST5 (20) & PCR & [19] \\
\hline $\begin{array}{l}\text { Indonesia } \\
\text { (Winyapu) }\end{array}$ & 93 & $87.1 \%$ & $\begin{array}{l}\text { ST1 + ST5 (12), ST2 + } \\
\text { ST5 (8), ST5 + ST7 (8), } \\
\text { ST1 + ST2 + ST5 (31), } \\
\text { ST5 (14) }\end{array}$ & $\begin{array}{l}\text { Microscopy } \\
\text { and PCR }\end{array}$ & [1] \\
\hline China (Shaanxi) & 560 & $74.8 \%$ & $\begin{array}{l}\text { ST1 (15), ST3 (6), ST5 } \\
\text { (397), ST10 (1) }\end{array}$ & PCR & [22] \\
\hline $\begin{array}{l}\text { Thailand } \\
\text { (Ayutthaya, } \\
\text { Kanchanaburi) }\end{array}$ & 87 & $46.0 \%$ & ST1 (2), ST5 (38) & PCR & [29] \\
\hline $\begin{array}{l}\text { Brazil (Triângulo } \\
\text { Mineiro) }\end{array}$ & 18 & $44.4 \%$ & ST1 (3) & $\begin{array}{l}\text { Microscopy } \\
\text { and PCR }\end{array}$ & [21] \\
\hline
\end{tabular}




\begin{tabular}{|llllll|}
\hline Countries/regions & $\begin{array}{l}\text { Sample } \\
\text { size }\end{array}$ & $\begin{array}{l}\text { Prevalence } \\
(\%)\end{array}$ & Subtypes (No.) & $\begin{array}{l}\text { Examination } \\
\text { methods }\end{array}$ & References \\
\hline $\begin{array}{l}\text { Thailand } \\
\text { (Nakhon Pathom) }\end{array}$ & 90 & $35.6 \%$ & $\begin{array}{l}\text { ST1 (6), ST2 (1), ST5 } \\
(25)\end{array}$ & PCR & [24] \\
$\begin{array}{l}\text { India (Tamil } \\
\text { Nadu) }\end{array}$ & 90 & $94.4 \%$ & Unidentified & Microscopy & {$[30]$} \\
\hline $\begin{array}{l}\text { China } \\
\text { (Heilongjiang) }\end{array}$ & 68 & $8.8 \%$ & ST5 (6) & PCR & [25] \\
\hline
\end{tabular}

So far, seven Blastocystis subtypes have been identified in pigs: ST1, ST2, ST3, ST5, ST6, ST7, and ST10 [22]. Among these subtypes, ST5 is the most common and was detected in 165 out of 174 Blastocystispositive pigs in this study. The predominance of the ST 5 subtype in pigs is also observed in most other countries, such as the United Kingdom, the United States, Vietnam, Australia, Cambodia, Indonesia, and Thailand, as well as China (Table 3). Moreover, ST5 has been detected in piggery workers [20, 23], indicating the significance of this subtype in the pork industry. In contrast, ST6 appears to be a common subtype in Osaka, Japan [15], and ST1 in Spain and Brazil [17, 21].

In the present study, an age-related difference in the prevalence of Blastocystis subtypes was observed. ST1 and ST3 were only detected in piglets, while only ST 5 was found in fattening pigs and sows (Table 3). This observation is in agreement with a study conducted in Shaanxi, in which only ST5 was identified in pigs of more than 6 months old [22]. This indicates that ST5 is primarily a host-adaptated subtype in pigs. However, there are probably no major geographic differences in the distribution of Blastocystis in pigs (Table 3).

\section{Conclusions}

A high prevalence of Blastocystis was detected in pigs in Xinjiang, China. The infection rate increased significantly with increasing age of the pigs. ST5 was the predominant Blastocystis subtype in all age groups, with a small number of ST1 and ST3 isolates being found in piglets. Subtypes ST1, ST3, and ST5 may emerge as zoonotic pathogens in some areas of China because of the large scale of the pork industry and close contact between pigs and humans. More studies are needed to elucidate the transmission and public health significance of Blastocystis in pigs in various areas.

\section{Abbreviations}

PCR: polymerase chain reaction; SSUrRNA: small subunit ribosomal RNA; ST: sequence type.

\section{Declarations}

\section{Acknowledgements}


We thank pig farm staff for assist in collecting samples.

\section{Ethics approval and consent to participate}

This study was performed in accordance with the recommendations in the Guide for the Care and Use of Laboratory Animals of the Ministry of Health, China. Prior to the experiment, the protocol of this study was approved by the Research Ethics Committee of Henan Agricultural University (Zhengzhou, China). The fecal samples were obtained by the collection of feces excreted from animals after the permission of farm owners, with no specific permits being required by the authority for the feces collection.

\section{Consent for publication}

Not applicable.

\section{Availability of data and materials}

Representative nucleotide sequences generated in this study were deposited in the GenBank database under accession numbers MN326610-MN326619.

\section{Competing interests}

The authors declare that they have no competing interests.

\section{Funding}

This work was supported in part by the National Natural Science Foundation of China (31672548, 31702227), and the Program for Young and Middle-Aged Leading Science, Technology, and Innovation of Xinjiang Production \& Construction Group (2018CB034).

\section{Authors' contributions}

$L X Z$, and $M Q$ conceived and designed the research. $Y Z$, and $Y X J$ collected the samples. RJW, YZ, JMX, and MQ performed the experiments. RJW, and DYT. analyzed the data. RJW wrote the manuscript. All authors have read and approved the final manuscript.

\section{Author details}

${ }^{1}$ College of Animal Science and Veterinary Medicine, Henan Agricultural University, Zhengzhou, Henan 450002, People's Republic of China. ${ }^{2}$ College of Animal Science, Tarim University, Alar, Xinjiang 843300, People's Republic of China.

\section{References}


1. Yoshikawa H, Tokoro M, Nagamoto T, Arayama S, Asih PB, Rozi IE. Syafruddin D. Molecular survey of Blastocystis from humans and associated animals in an Indonesian community with poor hygiene. Parasitol Int. 2016;65:780-4.

2. Wawrzyniak I, Poirier P, Viscogliosi E, Dionigia M, Texier C, Delbac F, Alaoui HE. Blastocystis, an unrecognized parasite: an overview of pathogenesis and diagnosis. Ther Adv Infect Dis. 2013;1:16778.

3. Cakir F, Cicek M, Yildirim IH. Determination the subtypes of Blastocystis and evaluate the effect of these subtypes on pathogenicity. Acta Parasitol. 2019;64:7-12.

4. Stensvold CR, Arendrup MC, Jespersgaard C, Mølbak K, Nielsen HV. Detecting Blastocystis using parasitological and DNA-based methods: a comparative study. Diagn Microbiol Infect Dis. 2007;59:303-7.

5. Santín M, Gómez-Muñoz MT, Solano-Aguilar G, Fayer R. Development of a new PCR protocol to detect and subtype Blastocystis from humans and animals. Parasitol Res. 2011;109:205-12.

6. Jiménez PA, Jaimes JE, Ramírez JD. A summary of Blastocystis subtypes in North and South America. Parasit Vectors. 2019;12:376.

7. Ren M, Song JK, Yang F, Zou M, Wang PX, Wang D, Zhang HJ, Zhao GH, Lin Q. First genotyping of Blastocystis in yaks from Qinghai Province, northwestern China. Parasit Vectors. 2019;12:171.

8. Stensvold CR, Alfellani MA, Nørskov-Lauritsen S, Prip K, Victory EL, Maddox C, Nielsen HV, Clark CG. Subtype distribution of Blastocystis isolates from synanthropic and zoo animals and identification of a new subtype. Int J Parasitol. 2009;39:473-9.

9. Alfellani MA, Taner-Mulla D, Jacob AS, Imeede CA, Yoshikawa H, Stensvold CR, Clark CG. Genetic diversity of Blastocystis in livestock and zoo animals. Protist. 2013;164:497-509.

10. Deng L, Chai Y, Zhou Z, Liu H, Zhong Z, Hu Y, Fu H, Yue C, Peng G. Epidemiology of Blastocystis infection in China: a systematic review. Parasite. 2019;26:41.

11. Yan Y, Su S, Ye J, Lai X, Lai R, Liao H, Chen G, Zhang R, Hou Z, Luo X. Blastocystis subtype 5: a possibly zoonotic genotype. Parasitol Res. 2007;101:1527-32.

12. Quilez J, Clavel A, Sanchez-Acedo C, Causape AC. Detection of Blastocystis in pigs in Aragon (Spain). Vet Parasitol. 1995;56:345-8.

13. Abe N, Nagoshi M, Takami K, Sawano Y, Yoshikawa H. A survey of Blastocystis in livestock, pets, and zoo animals in Japan. Vet Parasitol. 2002;106:203-12.

14. Thathaisong U, Worapong J, Mungthin M, Tan-Ariya P, Viputtigul K, Sudatis A, Noonai A, Leelayoova S. Blastocystis isolates from a pig and a horse are closely related to Blastocystis hominis. J Clin Microbiol. 2003;41:967-75.

15. Yoshikawa H, Abe N, Wu Z. PCR-based identification of zoonotic isolates of Blastocystis from mammals and birds. 2004;150:1147-51.

16. Rivera WL, Tan MA. Molecular characterization of Blastocystis isolates in the Philippines by riboprinting. Parasitol Res. 2005;96:253-7. 
17. Navarro C, Domínguez-Márquez MV, Garijo-Toledo MM, Vega-García S, Fernández-Barredo S, PérezGracia MT, García A, Borrás R, Gómez-Muñoz MT. High prevalence of Blastocystis in pigs reared under intensive growing systems: frequency of ribotypes and associated risk factors. Vet Parasitol. 2008;153:347-58.

18. Fayer R, Elsasser T, Gould R, Solano G, Urban JJr, Santín M. Blastocystis tropism in the pig intestine. Parasitol Res. 2014;113:1465-72.

19. Wang W, Cuttell L, Traub RJ, Owen H, Bielefeldt-Ohmann H. Characterization of the Blastocystisspecific faecal IgA immune response in pigs. Parasite Immunol. 2014;36:503-8.

20. Wang W, Owen H, Traub RJ, Cuttell L, Inpankaew T, Bielefeldt-Ohmann H. Molecular epidemiology of Blastocystis in pigs and their in-contact humans in Southeast Queensland, Australia, and Cambodia. Vet Parasitol. 2014;203:264-9.

21. Moura RGF, Oliveira-Silva MB, Pedrosa AL, Nascentes GAN, Cabrine-Santos M. Occurrence of Blastocystis in domestic animals in Triângulo Mineiro area of Brazil. Rev Soc Bras Med Trop. 2018;51:240-3.

22. Song JK, Hu RS, Fan XC, Wang SS, Zhang HJ, Zhao GH. Molecular characterization of Blastocystis from pigs in Shaanxi province of China. Acta Tropica. 2017;173:130-5.

23. Parkar U, Traub RJ, Vitali S, Elliot A, Levecke B, Robertson I, Geurden T, Steele J, Drake B, Thompson RC. Molecular characterization of Blastocystis isolates from zoo animals and their animal-keepers. Vet Parasitol. 2010;169:8-17.

24. Pintong AR, Sunyanusin S, Prasertbun R, Mahittikorn A, Mori H, Changbunjong T, Komalamisra C, Sukthana Y, Popruk S. Blastocystis subtype 5: predominant subtype on pig farms, Thailand. Parasitol Int. 2018;67:824-8.

25. Wang J, Gong B, Yang F, Zhang W, Zheng Y, Liu A. Subtype distribution and genetic characterizations of Blastocystis in pigs, cattle, sheep and goats in northeastern China's Heilongjiang Province. Infect Genet Evol. 2018;57:171-6.

26. Pakandl M. Occurrence of Blastocystis in pigs. Folia Parasitol (Praha). 1991;38:297-301.

27. Hu S, Liu Z, Yan F, Zhang Z, Zhang G, Zhang L, Jian F, Zhang S, Ning C, Wang R. Zoonotic and hostadapted genotypes of Cryptosporidium, Giardia duodenalis and Enterocytozoon bieneusi in dairy cattle in Hebei and Tianjin, China. Vet Parasitol. 2017;248:68-73.

28. Burden DJ, Anger HS, Hammer NC. Blastocystis infections in pigs. Vet Microbiol. 1978/1979;3:22734.

29. Udonsom R, Prasertbun R, Mahittikorn A, Mori H, Changbunjong T, Komalamisra C, Pintong AR, Sukthana Y, Popruk S. Blastocystis infection and subtype distribution in humans, cattle, goats, and pigs in central and western Thailand. Infect Genet Evol. 2018;65:107-11.

30. Arpitha GM, Sreekumar C, Latha BR, Vijaya Bharathi M. Prevalence and staining characteristics of Blastocystis isolates from food animals in Tamil Nadu. Vet Parasitol Reg. Stud Reports. 2018;11:615 . 


\section{Figures}

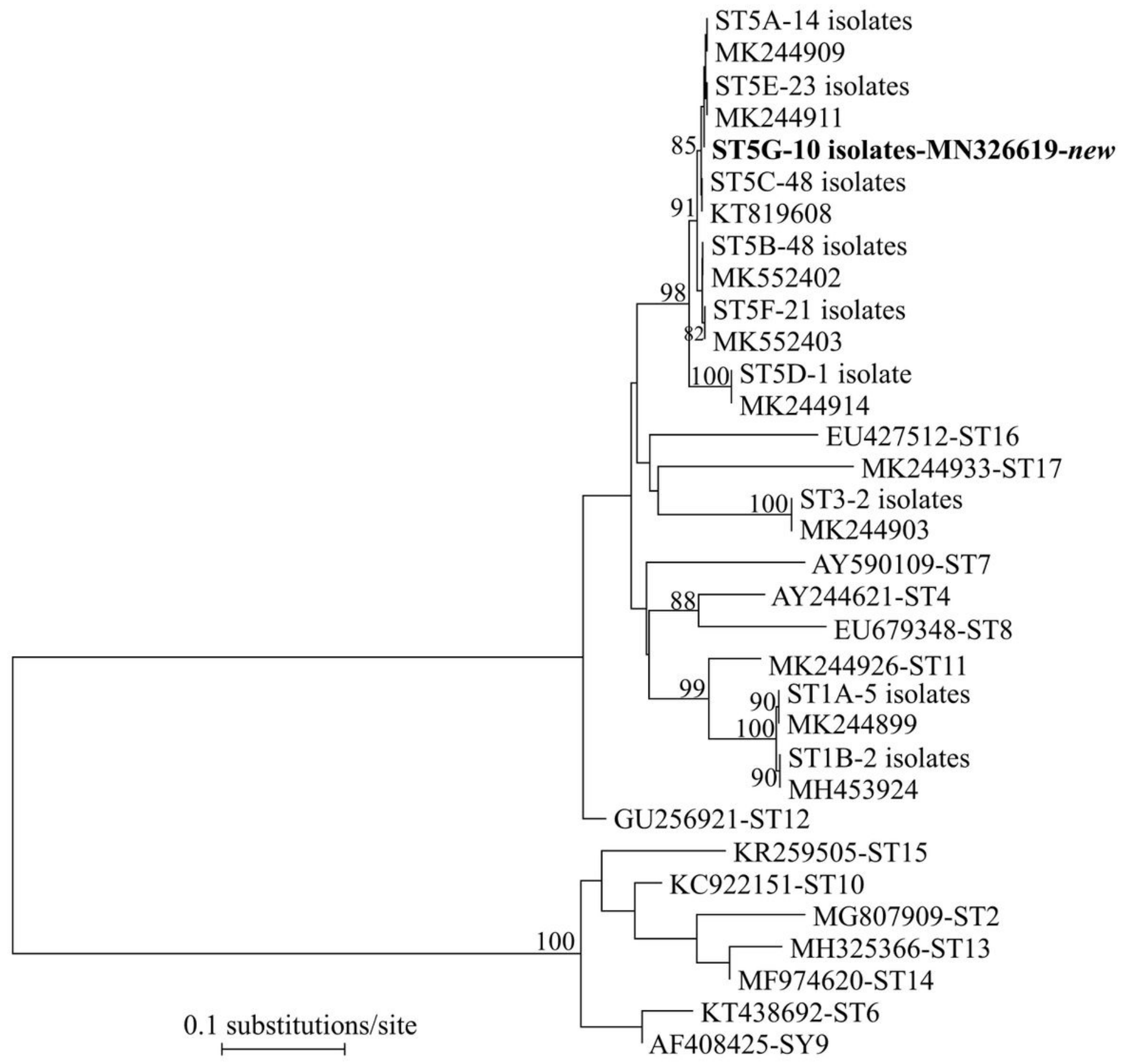

Figure 1

Phylogenetic relationships among representative sequences of the Blastocystis small subunit ribosomal RNA (SSU rRNA) genes, using the neighbor-joining method. Bootstrap values greater than $70 \%$ from 1,000 pseudoreplicates are shown. 